\title{
Positive psychological determinants of treatment adherence among primary care patients
}

\section{Sheri A. Nsamenang and Jameson K. Hirsch}

Laboratory of Rural Psychological and Physical Health, Department of Psychology, East Tennessee State University, TN, USA

\begin{abstract}
Background: Patient adherence to medical treatment recommendations can affect disease prognosis, and may be beneficially or deleteriously influenced by psychological factors. Aim: We examined the relationships between both adaptive and maladaptive psychological factors and treatment adherence among a sample of primary care patients. Methods: One hundred and one rural, primary care patients completed the Life Orientation Test-Revised, Trait Hope Scale, Future Orientation Scale, NEO-FFI Personality Inventory (measuring positive and negative affect), and Medical Outcomes Study General Adherence Scale. Findings: In independent models, positive affect, optimism, hope, and future orientation were beneficially associated with treatment adherence, whereas pessimism and negative affect were negatively related to adherence. In multivariate models, only negative affect, optimism and hope remained significant and, in a comparative model, trait hope was most robustly associated with treatment adherence. Implications: Therapeutically, addressing negative emotions and expectancies, while simultaneously bolstering motivational and goal-directed attributes, may improve adherence to treatment regimens.
\end{abstract}

Key words: hope; negative affect; optimism; pessimism; positive affect; treatment adherence

Received 20 August 2013; revised 23 April 2014; accepted 2 July 2014; first published online 27 August 2014

\section{Introduction}

Treatment adherence, or the degree to which a patient's behavior matches recommendations from a health care provider (Schlenk et al., 2001), is an essential component of achieving healthrelated goals and disease management. Yet, patient non-adherence ranges from $15 \%$ to $93 \%$, and it is estimated that four out 10 patients forget, misunderstand, or ignore treatment recommendations (Martin et al., 2005). Increased cost of health care, medical and psychosocial complications from

Correspondence to: Jameson K. Hirsch, PhD., Laboratory of Rural Psychological and Physical Health, Department of Psychology, East Tennessee State University, 420 Rogers Stout Hall, 37614 TN, USA. Email: hirsch@etsu.edu disease, and poor quality of life are consequences of poor treatment adherence (Herriman and Cerretani, 2007); as well, it is approximated that the cost of non-adherence is $\$ 300$ billion annually and 125000 deaths, in the United States (DiMatteo, 2004). On the other hand, an average of $26 \%$ of patients, across various disease groups, achieves good health outcomes as a consequence of adhering to treatment recommendations (DiMatteo et al., 2002). Treatment adherence has been associated with better outcomes for patients with alcohol dependence (Aguiar et al., 2012), headaches (Gaul et al., 2011), obsessive compulsive disorder (Simpson et al., 2011), and depression. (Sirey et al., 2010).

Conceptually, according to the World Health Organization (WHO, 2003), treatment adherence is a multidimensional phenomenon that is affected

(C) Cambridge University Press 2014 
by five dimensions: (1) social/economic factors such as lack of effective social support network, low level of education, and unemployment; (2) therapy-related factors such as duration of treatment, treatment side effects, and complexity of treatment regimens; (3) the health system/ health care team dimension, which refers to patient-provider relationship, status of health insurance reimbursement, and health worker burn out; (4) disease condition-related factors such as symptom severity, prognosis, and level of disability; and, (5) the patient-related dimension, which is comprised of patient attitudes, knowledge, perceptions, expectations, and beliefs.

At the level of the individual patient, characteristics such as fear of side effects, confusion and skepticism about treatment, or feelings of pessimism or low mood (Milam et al., 2004; Brunton, 2011), may negatively affect treatment adherence. Conversely, cognitive-emotional contributors to adaptive health functioning include, among others, positive affect, optimism, hopefulness, and future orientation. Such psychological factors tend to be stable and pervasive, affecting an individual's behaviors, thoughts and feelings (Allemand et al., 2013), including health behaviors and motivation to engage in treatment (Bosley et al., 1995). Importantly, research evidence, as well as theoretical support, suggests ambivalence toward self-health may be amenable to change, and this might be accomplished by addressing several key cognitive-emotional elements - mood and outlook (Rutter and Quine, 2002).

As an example, positive affect is an amalgamation of experiences such as enjoyment, love, and contentment, whereas negative affect is comprised of components such as fear, anger, distress, and sadness (Moneta et al., 2012). According to the Broaden-and-Build model, positive emotional experiences may beneficially expand an individual's cognitive and behavioral repertoire, including intellectual, social and physical resources, perhaps to include health behaviors and treatment adherence; conversely, negative affect might contribute to narrowing of an individual's cognitions and behaviors and, consequently, hinder treatment adherence (Fredrickson, 2001). In fact, positive affect has been found to promote health behaviors such as self-regulation against smoking (Shmueli and Prochaska, 2012), while negative affect has been associated with poor health information processing (Beckjord et al., 2008).
An expectancy of doubt versus confidence, rather than a mood, optimism is the general belief that the future will be positive, with positive outcomes to life experiences, whereas pessimism is the expectation of negative outcomes (Scheier and Carver, 1992). In general, optimism may promote health behaviors via active coping (Carver et al., 2010); further, according to expectancy-value theory, optimists may be more likely to adhere to treatment recommendations because optimistic expectations about treatment may result in a valuing of, and motivation toward, health or treatment goals (Carver and Scheier, 1998). Pessimism, alternatively, has been associated with denial and behavioral disengagement (Carver et al., 1993), use of passive coping strategies, and poor health behavior (Kubzansky et al., 2004).

Health goals must often be strived for, and hopefulness is a crucial component of success in such endeavors. Conceptualized as a motivational process of identifying, planning for and working toward attainment of a goal (Snyder, 2002; Bruininks and Malle, 2005), the construct of hope is closely associated with treatment adherence. Greater levels of hopefulness are associated with better overall health (Nekolaichuk et al., 1999), engagement in stroke aftercare (Arnaert et al., 2006), and fewer depressive symptoms (Visser et al., 2013). Conversely, hopelessness, is related to poor participation in treatment (Dunn et al., 2009), poor quality of life (Pompili et al., 2013), negative peceptions of health and health illness self-blame (Iliceto et al., 2010).

Perhaps intuitively, treatment adherence, as well as other pathways toward health-related goals and treatment adherence, may be dependent on extent of future orientation, or the ability for a person to envision expectations about and actions related to future goals (Nurmi, 2005; Hirsch et al., 2006). The ability to anticipate potential future scenarios, including health situations, may have motivational consequences for current health behavior; specifically, forethought and desire of a particular outcome may encourage goal identification, planning, and commitment (Lens et al., 2012), including engagement in health promotion behaviors (Crockett et al., 2009).

As a group, and across samples, positive affect, hope, optimism, and future orientation, and lower negative affect and pessimism, appear to be associated with self-determination and self-efficacy (Corrigan et al., 2012), which may motivate and 
facilitate treatment adherence. Although the aforementioned cognitive-emotional characteristics have been extensively studied with regard to health behaviors, including treatment engagement, no previously published research has examined these factors in the primary care setting, where their manifestation may be different. Understanding the association of these characteristics to treatment adherence in this setting is a crucial first step toward development of targeted interventions to promote adherence to health regimens. As such, we hypothesized that positive affect, optimism, hopefulness and future orientation would be significantly positively related to treatment adherence; and negative affect and pessimism would be inversely related, to treatment adherence, at the bivariate level, and at the multivariate level covarying age, sex and race/ethnicity.

\section{Methods}

\section{Participants}

Participants $(n=101)$ in this Institutional Review Board-approved study were recruited from a rural, primary care clinic serving working and uninsured patients, in a region of the United States identified as a Health Provider Shortage Area (Correll et al., 2011). Participants were primarily female $(n=71 ; 71 \%)$, White $(n=94 ; 94 \%)$, and had a mean age of $42.18(\mathrm{SD}=12.83)$. Our sample participants ranged from 18 to 64 years of age, and did not qualify for state-level insurance (Tenncare) or federal-level insurance (Medicare). Most participants $(n=46 ; 47 \%)$ reported an annual income less than $\$ 20000$, and 27 participants (28\%) earned less than $\$ 10000$; such incomes are not unexpected, as most of the nation's rural, poor receive their health care services from primary care providers (Ferrer, 2007). Further, six percent of our sample $(n=6)$ did not graduate high school, and only 25 persons $(25 \%)$ had obtained a college degree. Self-report data were collected over a oneyear period through in-person and online survey administration. Participants completed an informed consent process, and those who completed the survey materials were compensated with $\$ 15.00$.

\section{Measures}

The Medical Outcomes Study General Adherence Scale (MOS general adherence scale), a five-item measure, was used to assess general treatment adherence (Sherbourne et al., 1992). Items are rated on a 6-point Likert scale ranging from 1 (none of the time) to 6 (all of the time); for example, 'generally speaking, how often during the past 4 weeks were you able to do what the doctor told you?' The MOS general adherence scale has demonstrated acceptable internal reliability ( $\alpha=0.78)$ (Kravitz et al., 1993), including in primary care ( $\alpha=0.88)$ (Hamilton, 2003).

Trait positive affect and negative affect were assessed using the NEO Five-Factor Inventory (Costa and McCrae, 1992). Using sub-cluster item scoring, four items are utilized to assess trait positive affect and five items to assess trait negative affect (Chapman, 2007). Items are rated on a 5-point Likert scale ranging from 'strongly disagree' to 'strongly agree'. In previous research with a clinical sample, positive affect $(\alpha=0.68)$ had moderate internal reliability and negative affect $(\alpha=0.78)$ had acceptable internal reliability (Hirsch et al., 2007).

The Life Orientation Test-Revised (LOT-R) was used as a measure of dispositional optimism and pessimism (Scheier et al., 1994). The LOT-R consists of 10 items which are rated on a 5-point Likert scale ranging from 0 (strongly disagree) to 4 (strongly agree). Three items measure optimism (eg, 'Overall, I expect more good things to happen to me than bad'), three items measure pessimism (eg, 'I rarely count on good things happening to me'), and four items are fillers (eg, 'It's important for me to keep busy'). The LOT-R demonstrated acceptable internal consistency for optimism $(\alpha=0.71)$ and moderate internal consistency of pessimism $(\alpha=0.68)$, in a primary care sample (Herzberg et al., 2006; Hirsch et al., 2013).

Trait hope was measured by the composite score of the Trait Hope Scale (THS), which consists of eight items (Snyder et al., 1991). Items are rated on a 4-point Likert scale that ranges from 1 (definitely false) to 4 (definitely true); a sample item is: 'there are lots of ways around any problem'. Internal consistency for the THS ranges from 0.74 to 0.84 (Curry et al., 1997), and the measure has been previously used in a primary care sample (Hirsch et al., 2011).

Future orientation was measured using six items derived from the Reasons for Living InventoryOlder Adult Version (Edelstein et al., 2009). Items are rated on a Likert scale ranging from 1 (extremely 
Table 1 Means, standard deviations, and correlations

\begin{tabular}{|c|c|c|c|c|c|c|c|c|}
\hline Variables & $\mathrm{M}$ & SD & 1 & 2 & 3 & 4 & 5 & 6 \\
\hline 1. Positive affect & 3.48 & 0.77 & - & & & & & \\
\hline 2. Negative affect & 3.20 & 0.88 & $-0.52^{* *}$ & - & & & & \\
\hline 3. Optimism & 10.00 & 2.62 & $0.56^{* *}$ & $-0.63^{* *}$ & - & & & \\
\hline 4. Pessimism & 8.18 & 3.02 & $-0.54 * *$ & $0.63^{* *}$ & $-0.83^{* *}$ & - & & \\
\hline 5. Hopefulness & 5.55 & 1.49 & $0.53^{* *}$ & $-0.59 * *$ & $0.68 * *$ & $-0.70 * *$ & - & \\
\hline 6. Future orientation & 4.81 & 1.01 & $0.35^{* *}$ & $-0.37 * *$ & $0.47 * *$ & $-0.51 * *$ & $0.56 * *$ & - \\
\hline 7. Treatment adherence & 4.64 & 0.97 & $0.32 * *$ & $-0.37^{* *}$ & $0.39 * *$ & $-0.32^{* *}$ & $0.41 * *$ & $0.22 *$ \\
\hline
\end{tabular}

Optimism and pessimism = Life Orientation Test-Revised; Hopefulness = Trait Hope Scale; Future orientation = Future Orientation Scale; Positive affect and negative affect = NEO-FFI Personality Inventory; Treatment adherence = Medical Outcomes Study General Adherence Scale.

${ }^{*} P \leqslant 0.05,{ }^{*} P \leqslant 0.01$.

unimportant) to 6 (extremely important); sample item is: 'I have future plans I am looking forward to carrying out'. This scale has not been previously used with primary care patients but, in a clinical sample of depressed patients the six items demonstrated good internal consistency $(\alpha=0.91)$, with an average item-total correlation of 0.75 (Hirsch et al., 2006).

\section{Statistical analyses}

Pearson's product-moment correlations were used to examine zero-order associations between, and independence of, study variables. No correlation coefficients exceeded the cut-off recommended for multicollinearity $(r>0.80)$ (Katz, 2006), and all variables were retained in analyses. Hierarchical linear regression analyses were used to examine individual predictors of treatment adherence while controlling for age and sex. Additional multivariate models were analyzed, entering clusters of psychological variables simultaneously: (i) positive affect and negative affect; (ii) optimism and pessimism; and, (iii) trait hope and future orientation, as predictors. Finally, a multivariate model, using stepwise linear regression, was used to explore relative robustness of predictors.

Power analyses were conducted to ensure adequate sample size and to reduce risk for Type I error $(\alpha)$ and Type II error $(\beta)$ (Green, 1991; Tabachnick and Fidell, 2007). For regression analyses and desired medium effects, $\alpha=0.05$, and $\beta=0.20$, a sample size of $n \geqslant 50+8 m$ is necessary to assess multiple correlations, where $m$ refers to the number of independent variables in each model; our sample size of 101 exceeds the required 82 cases.

\section{Results}

In support of our hypotheses, at the bivariate level, greater positive affect $(r=0.32, P=0.001)$, optimism $(r=0.36, P<0.001)$, hopefulness $(r=0.41$, $P<0.001)$, and future orientation $(r=0.22, P=0.03)$ were associated with better self-reported treatment adherence. On the other hand, negative affect $(r=-0.37, P<0.001)$ and pessimism $(r=-0.32$, $P=0.001)$ were negatively related to treatment adherence (see Table 1).

In separate hierarchical regression analyses, pessimism, optimism, hopefulness, negative affect, and positive affect were independently associated with patient-reported treatment adherence. Meanwhile, future orientation was not significantly related to treatment adherence (see Table 2).

In a multiple regression model, with simultaneous entry of the predictors of positive and negative affect, only negative affect was significantly related to treatment adherence. In a model combining pessimism and optimism, optimism was associated with treatment adherence. Finally, in a model simultaneously examining trait hope and future orientation, trait hope was significantly related to treatment adherence (see Table 2). In an exploratory model, using stepwise regression, trait hope emerged as the characteristic most robustly associated with treatment adherence $(\beta=0.41$; $F(19.56), t=4.42, P<0.001)$.

\section{Discussion}

With a focus primarily on positive psychological variables amenable to brief treatment in primary 
Table 2 Hierarchical multiple regression analyses of psychological factors affecting treatment adherence

\begin{tabular}{|c|c|c|c|c|c|c|c|c|}
\hline \multirow[b]{2}{*}{ Variables } & \multicolumn{3}{|c|}{ Independent models } & \multirow[b]{2}{*}{$f^{2}$} & \multicolumn{3}{|c|}{ Multivariable models } & \multirow[b]{2}{*}{$f^{2}$} \\
\hline & $\mathrm{B}$ & $\mathrm{SE}$ & $\beta$ & & $\mathrm{B}$ & SE & $\beta$ & \\
\hline Age & 0.004 & 0.008 & 0.057 & & 0.004 & 0.008 & 0.057 & \\
\hline Sex & 0.004 & 0.215 & 0.002 & & 0.004 & 0.215 & 0.002 & \\
\hline Positive affect & 0.392 & 0.120 & $0.317 * *$ & 0.11 & 0.192 & 0.139 & 0.156 & \\
\hline Negative affect & -0.440 & 0.110 & $-0.404^{* * *}$ & 0.17 & -0.342 & 0.130 & $-0.314^{* *}$ & 0.20 \\
\hline Optimism & 0.149 & 0.035 & $0.409 * * *$ & 0.19 & 0.179 & 0.066 & $0.493 * *$ & \\
\hline Pessimism & -0.101 & 0.032 & $-0.318 * *$ & 0.11 & 0.031 & 0.057 & 0.099 & 0.20 \\
\hline Hopefulness & 0.266 & 0.061 & $0.414^{* * *}$ & 0.20 & 0.258 & 0.069 & $0.401 * * *$ & \\
\hline Future orientation & 0.205 & 0.097 & $0.216^{*}$ & 0.05 & 0.026 & 0.103 & 0.027 & 0.20 \\
\hline
\end{tabular}

Independent models = single IV; multivariable models = simultaneous IV's. Optimism and pessimism = Life Orientation Test-Revised; Hopefulness = Trait Hope Scale; Future orientation = Future Orientation Scale; Positive affect and negative affect $=$ NEO-FFI Personality Inventory; Treatment adherence = Medical Outcomes Study General Adherence Scale.

${ }^{*} P \leqslant 0.05,{ }^{* *} P \leqslant 0.01,{ }^{*}{ }^{*} P \leqslant 0.001 . f^{2}=$ effect size: $0.02=$ small, $0.15=$ small, $0.35=\operatorname{large}($ Cohen, 1988$)$.

care, we found that, after adjusting for age and sex in independent models, future orientation, optimism, pessimism, hope, negative, and positive affect were predictors of treatment adherence, supporting our hypotheses and previous research suggesting that treatment adherence is a multidimensional phenomenon affected by patientrelated factors (WHO, 2003; Brunton, 2011). Most previous research on treatment adherence has focused on patient demographic and socioeconomic factors (Rivero-Santana et al., 2013), whereas our study focuses on psychological and motivational factors. In independent models, all cognitive-emotional characteristics were associated with treatment adherence in expected directions. When pairs of variables were analyzed simultaneously, negative affect, optimism, and hopefulness were more robustly associated with patient-reported treatment adherence, than were positive affect, pessimism, and future orientation. Finally, when model contribution was assessed, trait hope emerged as most robustly associated with treatment adherence. In sum, it appears that treatment adherence may benefit from reduction of negative emotions, bolstering positive expectancies and, particularly, establishing and working toward health-related goals.

Consistent with support for the beneficial effect of optimism on healthy behaviors and active coping (Waldrop et al., 2001; Solberg-Nes and Segerstrom, 2006), our study suggests that optimism - even over and above the effects of pessimism - is associated with active treatment adherence. An optimistic belief that treatment recommendations will be successful, and that health or functionality will improve as a result, may increase treatment adherence (Karademas et al., 2011). Similarly, hopefulness, which is related to self-efficacy and strategic planning (Berg et al., 2011), was associated with treatment adherence. From a theoretical perspective, hopefulness may facilitate personal efficacy in identification, planning and movement toward treatment and health-related goals (Tong et al., 2010). Additionally, the goalsetting and motivational consequences of having positive expectations about the future may promote adaptive behavior engagement (Lens et al., 2012), such as treatment compliance. Conversely, individuals who are present-oriented or hold negative expectations about the future may have a limited sense of personal control (Crockett et al., 2009), perhaps affecting engagement in adaptive future health behaviors.

In contrast to the adaptive characteristics of optimism and hope, we found that negative affect, which may involve symptoms of anger, anxiety, and depression was associated with poor treatment adherence (Beckjord et al., 2008; Grindley et al., 2008). Mechanistically, negative affect may constrict an individual's thought-action repertoire and self-regulatory behaviors (Moskowitz et al., 2012), thus hindering the ability to adhere to treatment recommendations. Therapeutic efforts to reduce negative mood may be effective in encouraging patient involvement in the treatment process (Tice et al., 2007; Grindley et al., 2008). Curiously, both 
positive affect and future orientation failed to predict treatment adherence when included in multivariate models, suggesting that negative rather than positive affect, and that goal-orientation rather than simple future desires, are more robust contributors to treatment adherence.

Our novel findings must be interpreted in the context of minor limitations. Our sample of rural primary care patients was small, and was comprised of predominantly White females, which may limit generalizability. Further, because our volunteer participants self-selected into the study in response to flyers and brochures, we do not have information on the larger potential population from which our sample was drawn; thus, selection bias is possible, and sample representativeness is uncertain. Despite these issues, however, our sample was demographically similar to previous primary care samples (Probst et al., 2006), as well as to residents of the geographic area surrounding the clinic data collection site, according to US Census estimates (2014). Finally, our use of selfreport treatment adherence as an outcome is less than ideal, and may be subject to recall bias or social desirability effects, and our cross-sectional design limits the extent to which causal attributions can be discussed; therefore, our study should be replicated using objective, prospective assessments of diverse samples.

Previous research has strongly established the beneficial linkage between adaptive characteristics and health outcomes in medical samples; for instance, a supportive environment and social support network and positive affect are related to beneficial health outcomes including treatment adherence (DiMatteo, 1994; 2004; Hirsch et al., 2012); our study adds to this literature by expansion to a rural, primary care sample and by distinct focus on positive psychological functioning. In general, we found that positive psychological characteristics promote treatment adherence, and maladaptive psychological functioning, such as poor mood and outlook, are detrimental to compliance. Our findings may have clinical implications, which might be addressed by Behavioral Health Consultants in the primary care setting (Kolbasovsky et al., 2005). Decreasing negative affect, and increasing optimism and hopefulness, could be psychological targets that translate into better treatment adherence, perhaps via educational and affective interventions (Dolder, 2003).
Cognitive behavioral therapy strategies (Rains et al., 2006), such as re-appraisal of maladaptive cognitive distortions about treatment, and motivational interviewing techniques (Russell et al., 2011), such as eliciting change talk and self-affirmation, may promote a sense of positive mood and adaptive future orientation that facilitates health goaloriented behaviors including treatment adherence.

\section{References}

Aguiar, P.P., Neto, D., Lambaz, R., Chick, J. and Ferrinho, P. 2012: Prognostic factors during outpatient treatment for alcohol dependence: cohort study with 6 months of treatment follow-up. Alcohol and Alcoholism 47, 702-10.

Allemand, M., Steiger, A.E. and Hill, P.L. 2013: Stability of personality traits in adulthood: mechanisms and implications. Geropsych: The Journal of Gerontopsychology and Geriatric Psychiatry 26, 5-13.

Arnaert, A., Filteau, N. and Sourial, R. 2006: Stroke patients in the acute care phase. Holistic Nursing Practice 20, 137-46.

Beckjord, E., Finney Rutten, L.J., Arora, N.K., Moser, R.P. and Hesse, B.W. 2008: Information processing and negative affect: evidence from the 2003 Health Information National Trends Survey. Health Psychology 27, 249-57.

Berg, C.J., Ritschel, L.A., Swan, D.W., An, L.C. and Ahluwalia, J.S. 2011: The role of hope in engaging in healthy behaviors among college students. American Journal of Health Behavior 35, 402-15.

Bosley, C., Fosbury, J. and Cochrane, G. 1995: The psychological factors associated with poor compliance with treatment in asthma. The European Respiratory Journal 8, 899-904.

Bruininks, P. and Malle, B.F. 2005: Distinguishing hope from optimism and related affective states. Motivation and Emotion 29, 327-55.

Brunton, S.A. 2011: Improving medication adherence in chronic disease management. Journal Of Family Practice 60, S1-S8.

Carver, C.S., Pozo, C., Harris, S.D., Noriega, V., Scheier, M.F., Robinson, D.S., Ketcham, A.S., Moffat, F.L. and Clark, K.C. 1993: How coping mediates the effect of optimism on distress: a study of women with early stage breast cancer. Journal of Personality and Social Psychology 65, 375-90.

Carver, C.S. and Scheier, M.F. 1998: On the self-regulation of behavior. New York: Cambridge University Press.

Carver, C.S., Scheier, M.F. and Segerstrom, S.C. 2010: Optimism. Clinical Psychology Review 30, 879-89.

Chapman, B.P. 2007: Bandwidth and fidelity on the NEO-Five Factor Inventory: Replicability and reliability of Saucier's (1998) item cluster subcomponents. Journal of Personality Assessment 88, 220-34.

Cohen, J. 1988: Statistical power analysis for the behavioral sciences. Hillsdale, New Jersey: Lawrence Erlbaum Associates. 
Correll, J.A., Cantrell, P. and Dalton, W.T. III 2011: Integration of behavioral health services in a primary care clinic serving rural Appalachia: reflections on a clinical experience. Families, Systems \& Health 29, 291-302.

Corrigan, P.W., Angell, B., Davidson, L., Marcus, S.C., Salzer, M.S., Kottsieper, P., Larson, J.E., Mahoney, C.A., O'Connell, M.J. and Stanhope, V. 2012: From adherence to self-determination: evolution of a treatment paradigm for people with serious mental illnesses. Psychiatric Services 63 169-73.

Costa, P.T. and McCrae, R.R. 1992. Revised NEO Personality Inventory (NEO-PI-R) and NEO Five-Factor Inventory (NEO-FFI) professional manual. Odessa, FL: Psychological Assessment Resources Inc.

Crockett, R., Weinman, J., Hankins, M. and Marteau, T. 2009: Time orientation and health-related behaviour: measurement in general population samples. Psychology and Health 24, 333-50.

Curry, L.A., Snyder, C.R., Cook, D.L., Ruby, B.C. and Rehm, M. 1997: Role of hope in academic and sport achievement. Journal of Personality and Social Psychology 73, 1257-67.

DiMatteo, M.R. 1994: Enhancing patient adherence to medical recommendations. Journal of American Medical Association 271, 79-83.

DiMatteo, M.R. 2004: Social support and patient adherence to medical treatment: a meta-analysis. Health Psychololgy 23, 207-18.

DiMatteo, M.R. 2004: Evidence-based strategies to foster adherence and improve patient outcomes. Journal of the American Academy of Physician Assistants 17, 18.

DiMatteo, M., Giordani, P., Lepper, H. and Croghan, T. 2002: Patient adherence and medical treatment outcomes - a meta-analysis. Medical Care 40, 794-811.

Dolder, C.R., Lacro, J.P., Leckband, S. and Jeste, D.V. 2003: Interventions to improve antipsychotic medication adherence: review of recent literature. Journal of Clinical Psychopharmacology 23, 389-99.

Dunn, S.L., Stommel, M., Corser, W.D. and Holmes-Rovner, M. 2009: Hopelessness and its effect on cardiac rehabilitation exercise participation following hospitalization for acute coronary syndrome. Journal of Cardiopulmonary Rehabilitation and Prevention 29, 32-39.

Edelstein, B.A., Heisel, M.J., McKee, D.R., Martin, R.R., Koven, L.P., Duberstein, P.R. and Britton, P.C. 2009: Development and psychometric evaluation of the reasons for living - older adults scale: a suicide risk assessment inventory. The Gerontologist 49, 736-45.

Ferrer, R.L. 2007: Pursuing equity: contact with primary care and specialist clinicians by demographics, insurance, and health status. Annals of Family Medicine 5, 492-502.

Fredrickson, B.L. 2001: The role of positive emotions in positive psychology: the broaden-and-build theory of positive emotions. American Psychologist 56, 218-26.

Gaul, C., van Doorn, C., Webering, N., Dlugaj, M., Katsarava, Z., Diener, H.C. and Fritsche, G. 2011: Clinical outcome of a

Primary Health Care Research \& Development 2015; 16: 398-406 headache-specific multidisciplinary treatment program and adherence to treatment recommendations in a tertiary headache center: an observational study. Journal of Headache Pain 12, 475-83.

Green, S.B. 1991: How many subjects does it take to do a regression analysis? Multivariate Behavioral Research 26, 499-510.

Grindley, E.J., Zizzi, S.J. and Nasypany, A.M. 2008: Use of protection motivation theory, affect, and barriers to understand and predict adherence to outpatient rehabilitation. Physical Therapy 88, 1529-40.

Hamilton, G. 2003: Measuring adherence in a hypertension clinical trial. European Journal of Cardiovascular Nursing: Journal of The Working Group on Cardiovascular Nursing of The European Society of Cardiology 2, 219-28.

Herriman, E. and Cerretani, J. 2007: Patient non-adherence: pervasiveness, drivers, and interventions. IC Sciences Spotlight Series 2, 1-6.

Herzberg, P., Glaesmer, H. and Hoyer, J. 2006: Separating optimism and pessimism: a robust psychometric analysis of the Revised Life Orientation Test (LOT-R). Psychological Assessment 18, 433-38.

Hirsch, J.K., Duberstein, P.R., Chapman, B. and Lyness, J.M. 2007: Positive affect and suicide ideation in older adult primary care patients. Psychology and Aging 22, 380-85.

Hirsch, J.K., Duberstein, P.R., Conner, K.R., Heisel, M.J., Beckman, A., Franus, N. and Conwell, Y. 2006: Future orientation and suicide ideation and attempts in depressed adults ages 50 and over. The American Journal of Geriatric Psychiatry 14, 752-57.

Hirsch, J.K., Floyd, A. and Duberstein, P.R. 2012: Perceived health in lung cancer patients: the role of positive and negative affect. Quality of Life Research 21, 187-94.

Hirsch, J., Sirois, F. and Lyness, J. 2011: Functional impairment and depressive symptoms: mitigating effects of trait hope. British Journal of Health Psychology 16, 744-60.

Hirsch, J.K., Walker, K.L., Wilkinson, R.B. and Lyness, J.M. 2013: Family criticism and depressive symptoms in older adult primary care patients: optimism and pessimism as mediators. American Journal of Geriatric Psychiatry 22, 632-35.

Iliceto, P., Pompili, M., Girardi, P., Lester, D., Vincenti, C., Rihmer, Z., Tatarelli, R. and Akiskal, H. 2010: Hopelessness, temperament, and health perception in heroin addicts. Journal of Addictive Diseases 29, 352-58.

Karademas, E.C., Kynigopoulou, E., Aghathangelou, E. and Anestis, D. 2011: The relation of illness representations to the 'end-stage' appraisal of outcomes through health status, and the moderating role of optimism. Psychology and Health 26, 567-83.

Katz, M.H. 2006: Multivariable analysis: a practical guide for clinicians. New York, NY: Cambridge University Press.

Kolbasovsky, A., Reich, L. and Romano, I. 2005: Integrating behavioral health into primary care settings: a pilot project. Professional Psychology: Research \& Practice 36, 130-35.

Kravitz, R., Hays, R.D., Sherbourne, C.D., DiMatteo, M.R., Rogers, W.H., Ordway, L. and Greenfield, S. 1993: Recall of 
recommendations and adherence to advice among patients with chronic medical conditions: results from the Medical Outcomes Study. Archives of Internal Medicine 153, 1869-78.

Kubzansky, L.D., Kubzansky, P.E. and Maselko, J. 2004: Optimism and pessimism in the context of health: bipolar opposites or separate constructs? Personality and Social Psychology Bulletin 30, 943-56.

Lens, W., Paixao, M., Herrera, D. and Grobler, A. 2012: Future time perspective as a motivational variable: content and extension of future goals affect the quantity and quality of motivation. Japanese Psychological Research 54, 321-33.

Martin, L.R., Williams, S.L., Haskard, K.B. and DiMatteo, M.R. 2005: The challenge of patient adherence. Therapeutics and Clinical Risk Management 1, 189-99.

Milam, J.E., Richardson, J.L., Marks, G., Kemper, C.A. and Mccutchan, A.J. 2004: The roles of dispositional optimism and pessimism in HIV disease progression. Psychology and Health 19, 167-81.

Moneta, G.B., Vulpe, A. and Rogaten, J. 2012: Can positive affect "undo" negative affect? A longitudinal study of affect in studying. Personality and Individual Differences 53, 448-52.

Moskowitz, J., Shmueli-Blumberg, D., Acree, M. and Folkman, S. 2012: Positive affect in the midst of distress: implications for role functioning. Journal of Community and Applied Social Psychology 22 502-18.

Nekolaichuk, C.L., Jevne, R.F. and Maguire, T.O. 1999: Structuring the meaning of hope in health and illness. Social Science and Medicine 48, 591-605.

Nurmi, J. 2005: Thinking about and acting upon the future: development of future orientation across the life span. In Strathman, A. and Joireman, J., editors, Understanding behavior in the context of time: theory, research, and application. Mahwah, NJ: Lawrence Erlbaum Associates Publishers, 31-57.

Pompili, M., Pennica, A., Serafini, G., Battuello, M., Innamorati, M., Teti, E., Girardi, N., Amore, M., Lamis, D., Aceti, A. and Girardi, P. 2013: Depression and affective temperaments are associated with poor health-related quality of life in patients with HIV infection. Journal of Psychiatric Practice 19, 109-17.

Probst, J.C., Laditka, S.B., Moore, C.G., Harun, N., Powell, M.P. and Baxley, E.G. 2006: Rural-urban differences in depression prevalence: implications for family medicine. Family Medicine - Kansas City 38, 653.

Rains, J.C., Penzien, D.B. and Lipchik, G.L. 2006: Behavioral facilitation of medical treatment for headache - Part II: theoretical models and behavioral strategies for improving adherence. Headache: The Journal of Head and Face Pain 46, 1395-1403.

Rivero-Santana, A., Perestelo-Perez, L., Perez-Ramos, J., Serrano-Aguilar, P. and De Las Cuevas, C. 2013: Sociodemographic and clinical predictors of compliance with antidepressants for depressive disorders: systematic review of observational studies. Patient Preference and Adherence 7, 151-69.

Russell, C.L., Cronk, N.J., Herron, M., Knowles, N., Matteson, M.L., Peace, L. and Ponferrada, L. 2011: Motivational Interviewing in dialysis adherence study (MIDAS). Nephrology Nursing Journal 38, 229-36.

Rutter, D. and Quine, L. 2002. Changing health behaviour intervention and research with social cognition models. Philadelphia, PA: Open University Press.

Scheier, M.F. and Carver, C.S. 1992: Effects of optimism on psychological and physical well-being: theoretical overview and empirical update. Cognitive Therapy and Research 16, 201-28.

Scheier, M.F., Carver, C.S. and Bridges, M.W. 1994: Distinguishing optimism from neuroticism (and trait anxiety, selfmastery, and self-esteem): a re-evaluation of the life orientation test. Journal of Personality and Social Psychology 67, 1063-78.

Schlenk, E.A., Burke, L.E. and Rand, C. 2001: Behavioral strategies to improve medication-taking compliance. In Burke, L.E. and Ockene, I., editors, Compliance in healthcare and research. Armonk, NY: Futura Publishing Company Inc, 57-72.

Sherbourne, C.D., Hays, R.D., Ordway, L., DiMatteo, M.R. and Kravitz, R.L. 1992: Antecedents of adherence to medical recommendations: results from the medical outcomes study. Journal of Behavioral Medicine 15, 447-68.

Shmueli, D. and Prochaska, J.J. 2012: A test of positive affect induction for countering self-control depletion in cigarette smokers. Psychology of Addictive Behaviors 26, 157-61.

Simpson, H., Maher, M.J., Wang, Y., Bao, Y., Foa, E.B. and Franklin, M. 2011: Patient adherence predicts outcome from cognitive behavioral therapy in obsessive-compulsive disorder. Journal of Consulting and Clinical Psychology 79, 247-52.

Sirey, J., Bruce, M.L. and Kales, H.C. 2010: Improving antidepressant adherence and depression outcomes in primary care: the Treatment Initiation and Participation (TIP) Program. The American Journal of Geriatric Psychiatry 18, 554-62.

Snyder, C.R. 2002: Hope theory: rainbows in the mind. Psychological Inquiry 13, 249-75.

Snyder, C.R., Harris, C., Anderson, J.R., Holleran, S.A., Irving, L.M., Sigmon, S.T., Yoshinobu, L., Gibb, J., Langelle, C. and Harney, P. 1991: The will and the ways: development and validation of an individual-differences measure of hope. Journal of Personality and Social Psychology 60, 570-85.

Solberg-Nes, L. and Segerstrom, S. 2006: Dispositional optimism and coping: a metaanalytic review. Personality and Social Psychology Review 10, 235-51.

Tabachnick, B.G. and Fidell, L.S. 2007. Using Multivariate Statistics, fifth edition. Boston, MA: Pearson Education Inc.

Tice, D.M., Baumeister, R.F., Shmueli, D. and Muraven, M. 2007: Restoring the self: positive affect helps improve self-regulation following ego depletion. The Journal of Experimental Social Psychology 43, 379-84. 
Tong, E.M., Fredickson, B.L., Chang, W. and Lim, Z.X. 2010: Re-examining hope: the roles of agency thinking and pathways thinking. Cognition and Emotion 24, 1207-15.

Visser, P.L., Loess, P., Jeglic, E.L. and Hirsch, J.K. 2013: Hope as a moderator of negative life events and depressive symptoms in a diverse sample. Journal of the International Society for the Investigation of Stress 29, 82-88.
Waldrop, D., Lightsey, O.R. Jr, Ethington, C.A., Woemmel, C.A. and Coke, A.L. 2001: Self-efficacy optimism, health competence, and recovery from orthopedic surgery. Journal of Counseling Psychology 48, 233-38.

World Health Organization. 2003: Long-term therapies evidence for action. Geneva, Switzerland: World Health Organization. 